\title{
A New framework of e-Participation using data science to support community empowerment
}

\author{
Muhammad Yusuf ${ }^{1}$, Budi Dwi Satoto ${ }^{2}$, Sri Herawati ${ }^{3}$, Imamah $^{4}$ \\ Faculty of Engineering \\ University of Trunojoyo Madura \\ Bangkalan, Indonesia \\ ${ }^{1}$ muhammadyusuf@trunojoyo.ac.id, ${ }^{2}$ budids@trunojoyo.ac.id, ${ }^{3}$ sriherawati@trunojoyo.ac.id, ${ }^{4} \underline{12 m @ \text { trunojoyo.ac.id }}$
}

\begin{abstract}
Participation is an interesting field capturing how technology can support community empowerment in public decision making. Data Science is also an emerging field that uses methods, processes, algorithms and systems to develop pattern, knowledge and insights from tructured and unstructured data. It is still limited research capturing and integrating e-participation and data science into one framework. This paper aims to develop a new framework that integrate e-participation and data science frameworks. Hopefully, this research contributes a new framework of e-Participation using data science approach. The novel framework is collaborating technological and nontechnological aspects, multidisciplinary approaches and accommodating the emerging technologies nowadays. This research has implications for theory by adding the new framework into e-Participation, e-Government, Information Systems, Data Science fields. Another important practical implication is that practitioners and decision makers in government could consider elements in the framework to get successful in the technology implementation for supporting citizen participation
\end{abstract}

Keywords-A New framework; e-Participation; Data Science

\section{INTRODUCTION}

e-Participation is an interesting field capturing how community could be empowered in public decision making using technology. Participation is also needed in various areas, such as politics, public administration, business, and others. In politics and public administration, community can use e-voting to participate in decision making about public policy. Moreover, in business field, staffs of a company might have opportunity to give suggestion for improving the quality of the product. Data Science is also an emerging field that contain data mining and statistics to manipulate data and find out useful pattern to use the data. It is still limited research capturing and integrating e-participation and data science into one research. This paper aims to develop a new framework that integrate eparticipation and data science frameworks. Hopefully, this research contributes a new framework of e-Participation using data science approach. This research has implications for theory by adding the new framework into e-Participation, eGovernment, Information Systems, Data Science fields. For practice, practitioners and decision makers can use this framework to improve quality of e-Participation implementation using data science approach.

The brief structure of this paper consist of Introduction, Literature Reviews, Research Methods, Analysis and Discussions, as well as Conclusions sections.

\section{LITERATURE REVIEWS}

\section{A. E-Participation}

E-Participation is an emerging field that has various definitions, such as [1] explain e-participation refers to information and communication technologies (ICT) to support conversion of citizen participation in decision making process; According to [2] that defined e-participation as supporting citizen empowerment and open participation using ICT to improve information accessibility and public services and support citizen involvement in public policymaking. Additionally, [3] also defined e-participation as "the various dynamic activities of interaction, communication, participation and management through several electronic technologies, implemented by numerous stakeholders, such as internal, external, dominant and less dominant stakeholders, which are supported by support systems, influencing and influenced by many complex factors, changes, laws and policies as well as financial capital". Furthermore, there are existing EParticipation frameworks, such as [4] that developed three levels of participation for supporting e-democracy initiatives and policy making; [5] proposed a framework for evaluating eParticipation projects and tools; [6] capture a framework consist of various layers: the democratic processes, participation scope, participation techniques, tools classification and ICT technologies; [1] captured a model consists of elements of eParticipation actors, activities, effects, evaluation, contextual factors and the research approach; [7] also proposed a domain model of e-participation consists of the stakeholder, participation process and ICT Tool domains; [8] developed a framework of ICT application for E-Participation implementation; [9] captured a framework contains 7 stages: policy and capacity building, planning and goal settings, programs and contents development, process and tools, promotion, participation, postimplementation analysis; [10] proposed guidelines with six-step to help development and implementation of e-Participation projects; [11] examined an evaluation framework for e-participation in parliaments; [10] developed a framework for e-Participation projects contains a holistic engineering approach and supports communications between project actors with various levels of technical and political backgrounds from different perspectives; [12] proposed Actor-Network Theory (ANT) approach to develop eParticipation Framework in Malaysia; [13] emphazised a framework for evaluating the impact of eparticipation implementations; [14] developed a model for the e-participation framework; [15] also offered a model of e-participation based 
on school case studies in the UK and Indonesia; [3] proposed a generic model of e-participation; [16] developed a conceptual model that combine Internet of Things (IoT) and eParticipation.

\section{B. Data Science}

In this literature reviews, we would like to focus on data science frameworks as follows: [17] captured data science, data source, data scale, data story, and data scientists; [18] explained about data science expertise, venn diagrams, goals and deliverables, process, skills and education, data analysts and data engineers, also the data scientist's toolbox; [19] described data science definition, comparing data science with data analysis, process of data science, tools, skills, scope, advantages, how data science is different from big data; [20] explained data insight, data product, the skill set requirement, analytics and machine learning; [21] emphasized the life cycle of data science and data scientist profile; [22] presented structured and unstructured data, business intelligence and data science, life cycle, model planning and building tools; [23] reviewed about statistics and associated data science methods in bioimage informatics; [24] emphasized software for supporting big data science for data scientists and big data analytics frameworks based on clouds; [25] reviewed application of data science to materials microscopy, such as denoising, drift and distortion correction, spectral unmixing, and the use of simulated experiments to develop information about materials from microscopy data; [26] studied neural data science methods for analyzing neural time-series data with single-neuronal precision; Also, [27] explored emerging trends of big data technologies.

\section{RESEARCH METHODS}

This research is conducted based on desk research. The first stage is designing research methods. After that, we did literature reviews about esixting frameworks of e-participation and data science existing. Then, we developed a new framework of e-participation framework by adding data science elements. Furthermore, we analysed the new framework to identify advantages and disadvantages as well as other interesting things. Last stage, this research will emphasize conclusions, contributions and further research.

TABLE I. STEP BY STEP RESEARCH METHODS

\begin{tabular}{|c|l|l|}
\hline Step & \multicolumn{1}{|c|}{ Activity } & \multicolumn{1}{c|}{ Output } \\
\hline 1 & Designing research methods & $\begin{array}{l}\text { Step by step research } \\
\text { methods }\end{array}$ \\
\hline 2 & $\begin{array}{l}\text { Literature reviews about e- } \\
\text { Participation and Data Science } \\
\text { frameworks }\end{array}$ & $\begin{array}{l}\text { List of the existing e- } \\
\text { participation and data } \\
\text { science frameworks }\end{array}$ \\
\hline 3 & $\begin{array}{l}\text { Develop a new framework of e- } \\
\text { Participation using Data Science } \\
\text { approach }\end{array}$ & $\begin{array}{l}\text { A new framework of e- } \\
\text { Participation using Data } \\
\text { Science Approach }\end{array}$ \\
\hline 5 & $\begin{array}{l}\text { Analyse the advantages, limitations } \\
\text { and other interesting things of the } \\
\text { framework }\end{array}$ & $\begin{array}{l}\text { Analysis about the } \\
\text { advantages, limitations } \\
\text { and other interesting } \\
\text { things of the framework }\end{array}$ \\
\hline $\begin{array}{l}\text { Emphasize the conclusion, } \\
\text { conclusion and identify the further } \\
\text { research regarding collaboration } \\
\text { between e-Participation and Data } \\
\text { Science }\end{array}$ & $\begin{array}{l}\text { Conclusion, contribution } \\
\text { and further research }\end{array}$ \\
\hline
\end{tabular}

The existing frameworks of e-Participation were collected from various references, such as conference proceedings, journals, books and $\mathrm{PhD}$ dissertation of the first author. We searched the references from the Google Scholar engine by typing the keywords e-Participation, data science, framework, model. Furthermore, the relevant references were accessed and analysed.

\section{A PROPOSED FRAMEWORK}

The proposed framework is presented in the Fig. 1 below. It is a continuation work based on previous frameworks. The developed framework consist of a main part such as Stakeholders, Media, Object/Planning action, support system and data science approach. The stakeholders are wider stakeholders, NGO, citizen, government, politicians, researchers and others. The media consist of existing electronic technologies and Internet of Things (IoT). The existing electronic technologies are website, mobile, social media, radio, TV and others.

The IoT consist of perception, network and service (application) layers. The object/planning action include government and non-government $\operatorname{action}(\mathrm{s}) / \operatorname{activity}(\mathrm{s})$. The support systems are organization structure, procedures, trainings and others. The stakeholders have two ways interaction, communication, participation and management using media and the media have two ways interaction, communication, participation and management of object/planning action ( $\mathrm{s}$ ).

Furthermore, the stakeholders provide and receive support systems. It gives support to the two ways interaction, communication, participation and management. The main part of the model is influencing and influenced by financial capital, laws and policies, changes and complex factors. The complex factors consist of common, such as social, cultural, economy, politics and specific factors, such as weather and psychology of specific place and people. Those elements above are based on the previous research. Then, the elements of data science is added as an approach.

The data science approach consist of data sources, approach, tools and stages. Data structures consist of both structured and unstructured data in logs, cloud data, SQL, NoSQL, and text. Furthermore, the approaches are statistics, machine learning, graph analysis, neuro-linguistic programming (NLP). Moreover, the tools include RapidMiner, BigML, Weka, R, Python, SQL, Spark, Scala, Julia, Java, MySQL, Hadoop, Tableau and SAS. The stages consist of capture, maintain, process, analyze and communicate. The capture stage includes data acquisition, data entry, signal reception and data extraction. The maintain stage contains data warehousing, data cleansing, data staging, data processing and data architecture. Moreover, the processes are data mining, clustering/classification, data modeling and data 


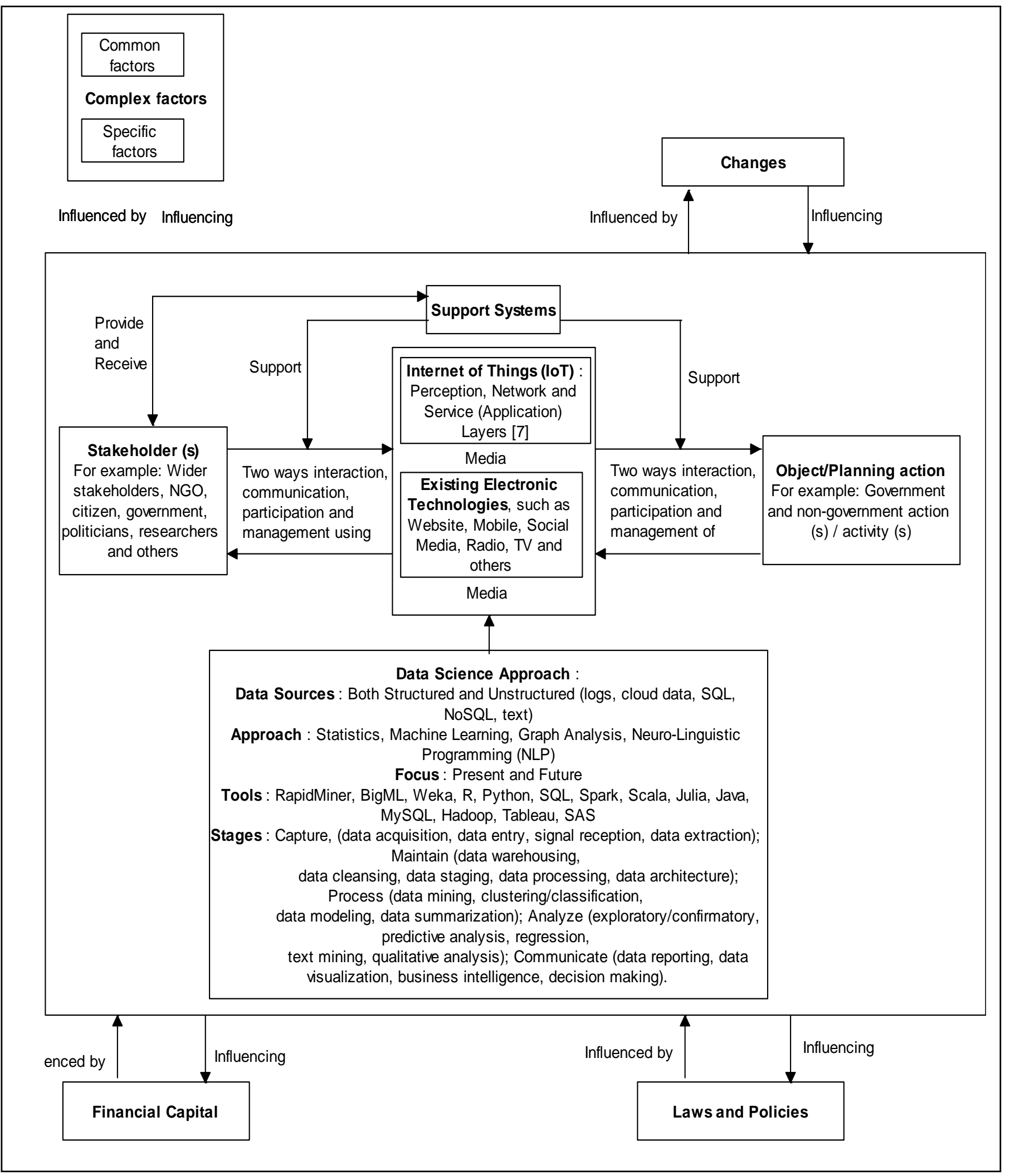

Fig. 1 A New Framework of e-Participation using Data Science Approach 
summarization. Furthermore, the analyze stages consist of exploratory/confirmatory, predictive analysis, regression, text mining and qualitative analysis. Then, the communicate stages include data reporting, data visualization, business intelligence and decision making. [17][18][19][20][21][22][23][24][25][26][27].

The framework in the figure 1 above has novelty by adding data science approach in the existing model of e-participation developed by [3] and [16]. Furthermore, the proposed framework above has some advantages as follows:

1. Collaborating multidisciplinary approach, such as finance, law, informatics, information system, management, public administration and specifically e-participation and data science fields.

3. Combining technological, such as website, mobile, Internet of Things (IoT) and non-technological aspects, such as finance, laws and policies.

4. Accommodating various and trending technologies and approach, such as and Data Science Approach.

Moreover, the developed framework also has limitations, such as it is still conceptual and has not been implemented in empirical research.

Data Science Approach has potential benefit to support digital community empowerment, especially in social media. Twitter, Facebook and other social media platforms have a lot of data that relevant with community encouragement. Therefore, data analytics of twitter and facebook could be very useful for practitioners and decision makers in government.

\section{CONCLUSIONS. CONTRIBUTIONS AND FURTHER RESEARCH}

The aim of the present research was to examine and develop a new framework of e-participation using data science approach. This study has shown that data science approach can be added in a novel framework of e-participation. The principal theoretical implication of this study is that this new framework can be develop body of knowledge for e-participation, data science, internet of things (IoT), informatics, information systems, law, management, public administration, finance fields. Another important practical implication is that practitioners and decision makers in government could consider elements in the framework to get successful in the technology implementation for supporting citizen participation. This work contributes to existing knowledge of e-Participation by providing a new framework of e-Participation using data science approach. A further study could explore the framework of e-Participation and deep learning.

\section{ACKNOWLEDGMENT}

We would like to thank our collagues at Faculty of Engineering University of Trunojoyo Madura for all supports and reviewers of this conference.

\section{REFERENCES}

[1] O. Saebo and L. S. Flak, "The shape of eParticipation: Characterizing an emerging research area," Government Information Quarterly, vol. 25, no. 3, pp. 400-428, 2008.

[2] D. M. D. E. a. S. A. United Nations, "Public Administration," 2016. [Online]. Available: https://publicadministration.un.org/en/eparticipation.

[3] M. Yusuf, C. Adams and K. Dingley, "Towards a Theory of EParticipation: An Actor-Network Theory (ANT) Perspective," University of Portsmouth, Portsmouth, 2017.

[4] A. Macintosh, "Characterizing e-Participation in policy making," in Proceedings of the 37th Annual Hawaii International Conference on Systems Sciences, Hawaii, 2004.

[5] E. Tambouris, N. Liotas and K. Tarabanis, "A Framework for Assessing eParticipation Projects and Tools," in The 40th Hawaii International Conference on System Sciences, Hawai, 2007.

[6] E. Tambouris, N. Liotas, D. Kaliviotis and K. Tarabanis, "A Framework for Scoping eParticipation," in The 8th Annual International Conference on Digital Government Research, Philadelphia, 2014.

[7] E. Kalampokis, E. Tambouris and K. Tarabanis, "A Domain model for eParticipation," in 3rd International Conference on Internet and Web Applications and Services, 2008

[8] C. W. Phang and A. Kankanhalli, "A Framework of ICT Expolitation for E-Participation Initiatives," Communications of the ACM, vol. 51, no. 12, pp. 128-132, 2008.

[9] M. S. Islam, "Towards a sustainable e-Participation implementation model," European Journal od ePractice, vol. 5, no. 10, pp. 1-12, 2008

[10]S. Scherer and M. A. Wimmer, "Reference Framework for EParticipation," in International Conference on Electronic Participation, Delft The Netherlands, 2011.

[11] E. Loukis, A. Xenakis and Y. Charalabidis, "An evaluation framework for e-participation in parliaments," International Journal of Electronic Governance, vol. 3, no. 1, pp. 1-22, 2010.

[12] M. A. Bin Salamat and S. Bin Hassan, "An Actor-Network Theory (ANT) approach to Malaysian e-Participation framework," in International Conference on Social Science and Humanity, Singapore, 2011.

[13] C. P. Espes, J. M. Moreno-Jimenez and M. A. Wimmer, "A Framework for Evaluating the Impact of E-Participation Experience," in Electronic Government and Electronic Participation Joint Proceedings of Ongoing Research, Posters, Workshop and Projects of IFIP EGOV 2014 and ePart 2014, 2014.

[14] S. Scherer and M. A. Wimmer, "A Metamodel for the E-Participation Reference Framework," in The International Conference on Electronic Participation, Guimaraes Portugal, 2016.

[15] M. Yusuf, C. Adams and K. Dingley, "Digital citizen participation within schools in the United Kingdom and Indonesia: An Actor-Network Theory (ANT) perspective," Information, vol. 7, no. 4, 2016.

[16] M. Yusuf, D. R. Anamisa and A. Khozaimi, "A Conceptual Model of Internet of Things (IoT) for e-Participation," in International Joint Conference of Science and Technology (IJCST), Bali, 2017.

[17] M. Loukides, "What is Data Science ?", Oreally, 2010.

[18] A. Castrounis, "What is Data Science, and What Does a Data Scientist Do?", innoarchitech, 2018

[19] Intellipaat, "What is Data Science ?", 2018.

[20] F. Lo, "What is Data Science?", Datajobs, 2018

[21] Berkeley, "What is Data Science, 2018

[22] H. Sharma, "What is Data Science ? A Beginner's Guide to Data Science", 2018.

[23]A. Chessel, "An Overview of Data Science uses in Bioimage Informatics", Methods, vol. 115, pp. 110-118.

[24] R. Elshawi, S. Sakr, D. Talia, P. Trunfio, "Big Data Systems meet Machine Learning Challenges: Towards Big Data Science as a Service", Big Data Research, 2018.

[25] P. M. Voyles, "Informatics and Data Sciencein materials microscopy", Current Opinion in Solid State and Materials Science, vol. 21, pp. 141$158,2017$. 
[26] L. Paninski and J.P. Cunningham, "Neural Data Science: Accelerating the experiment-analysis-theory cycle in large-scale neuroscience", Current Opinion in Neurobiology, vol. 50, pp. 232-241, 2018.

[27] N. Singh, "Emerging trends in technologies for Big Data", The International Technology Management Review, vol. 5, No. 4, pp. 202$210,2015$. 